\title{
Early postnatal alcohol exposure that produces high blood alcohol levels impairs development of spatial navigation learning
}

\author{
CHARLES R. GOODLETT, SANDRA J. KELLY, and JAMES R. WEST \\ University of Iowa College of Medicine, Iowa City, Iowa
}

\begin{abstract}
Artificial rearing procedures were used to expose groups of rats to alcohol during Postnatal Days 4 to 10. A 6.6-g/kg daily dose of ethanol was given either in a condensed fashion to induce cyclic daily blood alcohol concentrations (BACs) with high peaks or in a uniform fashion to induce stable, moderate daily BACs. Control groups included a gastrostomized, artificially reared group not exposed to alcohol and a suckle group. All artificially reared pups were fostered back to a dam on Postnatal Day 12. Beginning on Postnatal Day 19, the rats were tested daily in the Morris maze spatial navigation task. All measures of spatial navigation performance indicated that the group given the condensed alcohol exposure was significantly impaired in acquisition of spatial navigation. The group given uniform alcohol exposure differed only mildly from the control groups. The impairment of place learning of the condensed alcohol group suggests that the development of the hippocampal formation may have been impaired, consistent with findings that the neuromorphology of the hippocampus is significantly affected by condensed early postnatal alcohol exposure.
\end{abstract}

Since the first descriptions of the human fetal alcohol syndrome (Jones \& Smith, 1973; Jones, Smith, Ulleland, \& Streissguth, 1973; Lemoine, Harousseau, Borteryu, \& Menuet, 1968), it has become clear that heavy alcohol consumption by a pregnant woman can damage the development of the central nervous system (CNS) of the fetus. Learning disabilities and retarded behavioral development can be detected, even in cases in which the full complement of characteristics of the fetal alcohol syndrome are not present (Streissguth, 1986). Experimental research using a variety of animal model systems and methods has confirmed the teratogenic effects of alcohol both on the brain and on behavior (West, 1986).

Over the past several years, we have used artificial rearing of rat pups to examine the neuromorphological effects of alcohol exposure during the first 10 days of postnatal life (Pierce \& West, 1986a, 1986b, in press; West \& Hamre, 1985; West, Hamre, \& Pierce, 1984; West, Kelly, \& Pierce, 1987). In terms of brain development, this period in the rat shares many characteristics with the human third trimester (Dobbing \& Sands, 1973, 1979). In particular, it includes the time of most rapid increase in brain size and includes synaptogenesis and proliferation of the microneuron populations (Dobbing, 1981). We have found that alcohol exposure during this "third

We thank Sara Hulsether for help with the behavioral testing and data analysis and John Nichols for his assistance with the data analysis and his excellent proofreading. This study was supported by Grant AA05523 from the National Institute on Alcohol Abuse and Alcoholism to J. R. W.

Please address all correspondence to: James R. West, Alcohol and Brain Research Laboratory, Department of Anatomy, College of Medicine, University of Iowa, Iowa City, IA 52242. trimester equivalent" causes severe restriction of brain growth in rats without affecting body weight and that the level of alcohol exposure, as indicated by blood alcohol concentrations (BACs), is a major determinant of the severity of microencephaly (Pierce \& West, 1986a, 1986b; West, Kelly, \& Pierce, in press). Continuous exposure to alcohol from Postnatal Days 4 to 10 leads to BAC-dependent reductions of brain-weight/body-weight ratios (measured on Postnatal Day 10), with the threshold of microencephaly effects occurring when BACs reached approximately $190 \mathrm{mg} / \mathrm{dl}$ (Pierce \& West, 1986a). Recently we have shown that a dose that is subthreshold for producing microencephaly when administered continuously $(6.6 \mathrm{~g} / \mathrm{kg} /$ day $)$ severely restricts brain growth as measured on Postnatal Day 10 when the dose is condensed into $8 \mathrm{~h}$ of each 24-h period during Postnatal Days 4 to 10 (Pierce \& West, in press; West, Kelly, \& Pierce, 1987). In this condensed dose regimen, BACs are cyclic and reach peaks of about $400 \mathrm{mg} / \mathrm{dl}$ and approach zero during each alcohol-free period. Importantly, the brain growth restriction produced by this condensed pattern of exposure is still evident in rats allowed to survive to adulthood (West, Kelly, \& Pierce, 1987).

Brain growth is a rather crude measure of teratogenic effects of alcohol and cannot answer the question of whether particular brain regions may be vulnerable to damage. For example, we showed that both gestational exposure and early postnatal exposure to alcohol produced abe.iant development of the hippocampal mossy fibers in rats, but the effects were more severe with the early postnatal exposure than with gestational exposure (West \& Hamre, 1985). Areal measures of the CA fields of the hippocampus proper and of the dentate gyrus from rats 
given early postnatal alcohol exposure indicated that the size of the hippocampus proper, but not that of the dentate gyrus, was significantly reduced (Pierce $\&$ West, in press). This suggests that the morphology and/or the numbers of the prenatally generated hippocampal pyramidal neurons (Bayer, 1980; Schlessinger, Cowan, \& Swanson, 1978) are affected by the alcohol exposure during Postnatal Days 4 to 10 , whereas the granule cells, which are generated mostly postnatally (Schlessinger, Cowan, \& Gottlieb, 1975) may be less affected. Thus, neuromorphological data indicate that the hippocampus is susceptible to insult by early postnatal alcohol exposure and suggest that behaviors associated with hippocampal function may be affected by fetal alcohol exposure.

Vulnerability of the hippocampus to damage by early alcohol exposure has been implicated also from behavioral findings following prenatal exposure to alcohol in rodents. A number of studies have shown that rats and mice exposed to alcohol in utero exhibit behavioral effects consistent with hippocampal dysfunction, including developmental hyperactivity and impaired inhibitory avoidance learning (Bond, 1986; Bond \& DiGiusto, 1978; Gilliam, Stillman, Dudek, \& Riley, 1986; Riley, Barron, \& Hannigan, 1986; Riley, Lochry, \& Shapiro, 1979). However, behavioral effects of alcohol exposure during the third trimester equivalent have not been examined extensively. Recent findings in this lab have demonstrated that the condensed pattern of exposure that produces permanent microencephaly also produces hyperactivity in developing pups (Kelly, Hulsether, \& West, 1986; West, Kelly, \& Pierce, 1987) and that the hyperactivity is also present in adults (Kelly, Pierce, \& West, in press). The present study is the first report of the effects of alcohol in the third trimester equivalent rat model on learning and uses a task thought to depend on the functional integrity of the hippocampus.

The task chosen to serve as a developmental behavioral assay of hippocampal function was one specifically linked to hippocampal function in adult rats-spatial navigation in the Morris water maze (Morris, 1981). This task requires rats to locate, on the basis of distal, extramaze spatial cues, a small platform hidden under the surface of the water in a large tank. The task has been shown to be sensitive to a variety of experimental insults to the hippocampal formation or closely linked structures (Morris, Garrud, Rawlins, \& O'Keefe, 1982; Sutherland, Kolb, \& Whishaw, 1982; Sutherland, Whishaw, \& Kolb, 1983), as well as insults to cortical structures (Kolb, Sutherland, \& Whishaw, 1983; Whishaw \& Kolb, 1984). Acquisition of spatial navigation was shown to improve as a function of age from weaning to adulthood (Schenk, 1985). Moreover, Dyck, Sutherland, and Buday (1985) demonstrated that pups tested daily, beginning on Postnatal Day 15, did not show efficient performance in the Morris maze until around Postnatal Day 24, and that rats sustaining neonatal damage to dentate granule cells failed to develop efficient performance of the spatial navigation task. This suggests that spatial performance is correlated with the functional development of the hippocampal circuitry and its late-developing connections (Dyck et al., 1985), a contention supported by the improvement of spatial learning acquisition rates over development in normal rats (Schenk, 1985). If the functional development of the hippocampus is affected as a consequence of alcohol's effects on the morphology of the hippocampus and the mossy fiber system (Pierce \& West, in press; West \& Hamre, 1985), then the Morris maze task should be sensitive to fetal alcohol effects. Thus, we compared the development of spatial learning in the Morris maze in rats given the condensed alcohol exposure regimen or the uniform alcohol exposure regimen discussed earlier $(6.6 \mathrm{~g} / \mathrm{kg} /$ day $)$ with the performance of normally reared and artificially reared controls.

\section{METHOD}

\section{Subjects}

Fifty-five Sprague-Dawley rats from eight litters born in our colony from timed pregnancies were used in the study. Gestational Day I was established on the Ist day that the vaginal smear indicated the presence of sperm. Gestational Day 22 was then defined as Postnatal Day 1, even if gestational periods were variable. Except during the artificial rearing period, the dams and their pups were given free access to food and water in the vivarium. Weaning occurred on Postnatal Day 21, after which the offspring were group housed with littermates. The litters were group housed by sex on Postnatal Day 30.

\section{Artificial Rearing}

On Postnatal Day 4, the pups of the litter were assigned randomly to one of the four experimental groups: suckle controls (Group SC), gastrostomy controls (Group GC), uniform alcohol exposure (Group UA), and condensed alcohol exposure (Group CA) (group $n$ s are shown in Table 1). The rats that were to be reared artificially were anesthetized lightly with ether and implanted with gastrostomy feeding tubes (Samson \& Diaz, 1982). Each pup was placed in a plastic cup floating in an aerated, heated water bath $\left(37^{\circ} \mathrm{C}\right)$. The bottom of the plastic cup was covered with small wood chips. A timer-controlled infusion pump (Harvard Apparatus Model 935) fed milk formula to the rats through their gastrostomy tubes every $2 \mathrm{~h}$ for $20 \mathrm{~min}$ (see West, Hamre, \& Pierce, 1984, for detailed description). Each day, they received a total volume (in milliliters) of formula equal to $33 \%$ of the mean body weight (in grams) of the litter. Each morning between 0820 and $1000 \mathrm{~h}$, the artificially reared rats were bathed and given $0.1 \mathrm{ml}$ of distilled water through their gastrostomy tubes. Their anal/genital areas were stroked in order to facilitate excretion. All pups were weighed each day.

\section{Experimental Groups}

The pups to be reared artificially were removed from the litter on Postnatal Day 4 and replaced with nonexperimental pups of the same age from a different litter. Thus, litter size for Group SC was maintained between 8 and 12 pups throughout the preweaning period. The artificially reared Group UA received milk solution that was $2.5 \%(\mathrm{v} / \mathrm{v})$ ethanol for all 12 feedings in a $24-\mathrm{h}$ period. Group CA was given milk solution that was $7.5 \%(v / v)$ ethanol for 4 feedings (resulting in a total of $8 \mathrm{~h}$ of exposure each day) and milk formula alone for the remaining 8 daily feedings. This ensured that both alcohol-exposed groups received a total of $6.6 \mathrm{~g} / \mathrm{kg}$ of ethanol per day. Group GC received the milk formula with maltose-dextrin added such that the solution was isocaloric with the $2.5 \%$ alcohol solution. These treatments were given for a total of 72 feedings (Postnatal Days 4 to 10), and then, to allow the rats 
given alcohol 2 days of withdrawal before being fostered to a dam, all the rats were switched to milk formula alone for the 73rd to 96th feedings (Postnatal Days 10 and 11 ).

On Postnatal Day 12, after the 96th feeding, the artificially reared rats had their gastrostomy tubes cut and sealed. Both the artificially and normally reared rats were then coded arbitrarily by injecting their paws with india ink (Geller \& Geller, 1966) so that the researcher would be blind to the treatment groups during testing. The pups were then wiped with a slurry made from a dam's feces and fostered to that dam after the nonexperimental pups that had been added on Postnatal Day 4 were removed.

\section{Blood Alcohol Concentrations}

On the afternoon of Postnatal Day 6 and the morning of Postnatal Day 7, all of the artificially reared rats had 20- $\mu$ l samples of blood taken from the clipped ends of their tails. The samples were taken 90 min after a feeding so that the maximum tail blood alcohol concentration would be measured (Kelly, Bonthius, \& West, in press; West, Hamre, \& Pierce, 1984). The samples were taken $16 \mathrm{~h}$ apart so that Group CA had finished the last of the four daily feedings of $7.5 \%$ alcohol solution on Day 6 and had finished the last of the eight alcohol-free formula feedings on Day 7 . The blood samples from the rats, as well as alcohol-containing standards, were analyzed with an enzymatic assay kit (Sigma Chemical Co., Cata$\log$ No. 332-UV).

\section{Morris Maze Testing}

The training procedure used a circular white tank $(122 \mathrm{~cm}$ in diameter, $61 \mathrm{~cm}$ deep) filled to a depth of $46 \mathrm{~cm}$ with $23^{\circ} \mathrm{C}$ water. Two liters of powdered milk were dissolved in the water to make it relatively opaque. A small white wooden platform $(11 \times 12 \mathrm{~cm})$ was present in the same location on each acquisition trial, $30 \mathrm{~cm}$ from the wall of the tank. The platform was submerged $2 \mathrm{~cm}$ beneath the surface of the milky water. The homogeneous white environment of the maze prevented the use of local visual or olfactory cues in finding the platform; the rats had to learn to use distal (primarily visual) extramaze spatial cues available in the room around the tank to locate the platform efficiently (Morris, 1981).

The behavioral testing was performed with the experimenters blind to the experimental group, since the rats were identified by their paw marks made on Day 12. Testing commenced on Postnatal Day 19, and all rats were tested until Postnatal Day 30. Testing continued beyond Day 30 for any rats that had not met a relatively loose performance criterion (see below), either until the criterion was reached or until Day 40 . Each rat was given four daily trials separated by an intertrial interval of approximately $4 \mathrm{~min}$. During the intertrial interval, the rats were kept in an incubator with the temperature maintained at $30^{\circ} \mathrm{C}$. Each trial started when the rat was placed in the water; the rat was placed so that it faced the wall of the tank in one of four different compass points, and the order of starting positions was randomized across days. The rat was given a maximum of $45 \mathrm{sec}$ on each acquisition trial to find the platform and escape from swimming. After reaching the platform, it was allowed to remain there for $15 \mathrm{sec}$. Any rat that left the platform before the end of the 15-sec period was returned to the platform until the interval was complete. The latency to reach the platform was timed with a stopwatch, and the swimming paths for each trial were drawn onto scaled diagrams of the tank. A single practiced experimenter, who remained in the same location throughout the testing, was able to test the rats and record accurately the latencies and path diagrams without difficulty. On Postnatal Days 20, 26, and 30 (and after the last criterion day for those rats not meeting the criterion by Day 30), an additional $30-\mathrm{sec}$ trial, in which the platform was removed from the tank, was interposed between the second and third acquisition trial (or after the fourth trial for those tested beyond Day 30). The paths recorded for the probe trials were used to characterize the search strategies of the groups over the course of training.
When the first litter of rats reached Postnatal Day 30, it was clear that some had yet to perform efficiently. Therefore, we established a performance criterion of 2 consecutive days on which the platform was to be found in $10 \mathrm{sec}$ or less on three of the four daily trials, or on which the mean daily latency to reach the platform was $10 \mathrm{sec}$ or less. Any rat that had not met this criterion by the end of Day 30 testing was continued on the training regimen until the criterion had been met or until Day 40 . Those rats that had met the criterion by Day 30 were not tested further.

\section{Data Analysis}

The path diagrams for each trial were traced onto a Houston Instruments digitizing tablet interfaced with an IBM-AT computer, and path lengths were calculated using an SMI image analysis system. The angles at which the rats initially swam relative to the direct line to the platform (initial heading angles) were obtained using the same computerized system. This initial heading angle was measured from the point at which the rat had traveled $25 \mathrm{~cm}$ from the starting point of each trial. The mean daily latencies, the mean daily path lengths, and the mean daily initial heading angles of each rat during the Postnatal Day 19-Day 30 training period given to all rats were analyzed using a three-way, mixed-model repeated measures analysis of variance (ANOVA) (Keppel, 1982), with sex and rearing condition (suckle controls, gastrostomy controls, uniform alcohol exposure, or condensed alcohol exposure) as between-groups factors and training day as the repeated factor. Days to criterion, number of criterion days during the Day 19-Day 30 period, and number of trials in which the rats failed to reach the platform were analyzed using a two-way completely randomized factorial ANOVA, with rearing condition and sex as the between-groups factors. Post hoc comparisons were made using Newman-Keuls tests.

The probe trials, in which the platform was removed from the tank, were inspected for evidence that the groups differed in terms of their strategies in searching for the platform. Spatial strategies frequently are quantified in these probe trials by measuring the percentage of the path (or time) spent in the vicinity of the usual location of the platform (e.g., Goodlett, Valentino, Morgane, \& Resnick, 1986; Morris, 1981; Schenk, 1985). In the present study, the group differences in the search behavior on the three probe trials were demonstrated clearly by an easily obtained measure--the number of times the rat crossed the area where the platform was located (during the training trials), relative to the crossings of a similar area in the other three quadrants of the tank. Thus, these measures, referred to as annulus crossings, were analyzed separately at each day (Day 20, Day 26, and the last day) with a mixed-model repeated measures ANOVA, with rearing condition and sex as the betweengroups factors and quadrant as the repeated factor. Because data from the last probe trial of 2 rats in Group CA and one rat in Group GC were not available, the analysis of the last day's probe trial was based on 11 rats in Group CA and 14 rats in Group GC.

Body weights over the artificial rearing period and training period were transformed geometrically into areas under the curve, and these scores were analyzed with a two-way factorial ANOVA with sex and rearing condition as the between-groups factors. The BAC data of Groups UA and CA were analyzed with a two-way, mixed-model repeated measures ANOVA with type of alcohol exposure and sex as between-groups factors and time of blood sampling as the repeated factor. All post hoc comparisons were made using Newman-Keuls tests.

\section{RESULTS}

\section{Body Growth}

Body weights over the experimental period are shown in Table 1. Analysis of the area under the curves of body growth revealed that there were no significant group or sex differences in body weight. 
Table 1

Mean $( \pm S E M)$ Body Weights During the Experimental Period and Blood Alcohol Concentrations (BACs) of Groups Exposed to Alcohol

\begin{tabular}{|c|c|c|c|c|c|c|c|c|}
\hline & \multicolumn{6}{|c|}{ Body Weights (g) } & \multicolumn{2}{|c|}{ BACs $(\mathrm{mg} / \mathrm{dl})^{*}$} \\
\hline & $n$ & Day 4 & Day 10 & Day 12 & Day 21 & Day 30 & Day 6 (p.m.) & Day 7 (a.m.) \\
\hline $\begin{array}{l}\text { Group SC } \\
\text { Male } \\
\text { Female } \\
\text { Combined }\end{array}$ & $\begin{array}{r}6 \\
8 \\
14\end{array}$ & $\begin{array}{l}10.6 \\
10.1 \\
10.3\end{array}$ & $\begin{array}{l}20.3 \pm 0.4 \\
20.5 \pm 1.0 \\
20.4 \pm 0.6\end{array}$ & & $\begin{array}{l}50.0 \pm 3.1 \\
47.9 \pm 2.8 \\
48.8 \pm 2.1\end{array}$ & $\begin{array}{l}75.4 \pm 6.6 \\
75.2 \pm 5.2 \\
75.3 \pm 4.1\end{array}$ & - & $\begin{array}{l}- \\
- \\
-\end{array}$ \\
\hline $\begin{array}{l}\text { Group GC } \\
\text { Male } \\
\text { Female } \\
\text { Combined }\end{array}$ & $\begin{array}{r}7 \\
8 \\
15\end{array}$ & $\begin{array}{l}11.8 \pm 0.5 \\
11.6 \pm 0.5 \\
11.7 \pm 0.4\end{array}$ & $\begin{array}{l}24.8 \pm 1.0 \\
22.8 \pm 1.3 \\
23.8 \pm 0.8\end{array}$ & $\begin{array}{l}30.2 \pm 0.6 \\
27.2 \pm 1.0 \\
28.6 \pm 0.7\end{array}$ & $\begin{array}{l}49.7 \pm 2.1 \\
44.7 \pm 2.7 \\
47.0 \pm 1.8\end{array}$ & & - & $\begin{array}{l}- \\
-\end{array}$ \\
\hline $\begin{array}{l}\text { Group UA } \\
\text { Male } \\
\text { Female } \\
\text { Combined }\end{array}$ & $\begin{array}{r}7 \\
6 \\
13\end{array}$ & $\begin{array}{l}11.5 \pm 0.6 \\
11.7 \pm 0.4 \\
11.6 \pm 0.4\end{array}$ & $\begin{array}{l}23.7 \pm 0.5 \\
24.2 \pm 0.8 \\
24.0 \pm 0.5\end{array}$ & $\begin{array}{l}29.3 \pm 0.6 \\
28.4 \pm 1.4 \\
28.9 \pm 0.7\end{array}$ & $\begin{array}{l}47.4 \pm 1.8 \\
46.1 \pm 2.7 \\
46.8 \pm 1.5\end{array}$ & $\begin{array}{l}85.0 \pm 4.6 \\
69.2 \pm 4.0 \\
77.7 \pm 3.7\end{array}$ & $\begin{array}{c}151.8 \pm 43.2 \dagger \\
71.9 \pm 36.4 \\
111.8 \pm 29.5\end{array}$ & $\begin{array}{r}147.3 \pm 42.7 \\
57.2 \pm 42.7 \\
102.3 \pm 31.8\end{array}$ \\
\hline $\begin{array}{l}\text { Group CA } \\
\text { Male } \\
\text { Female } \\
\text { Combined }\end{array}$ & $\begin{array}{r}7 \\
6 \\
13\end{array}$ & $\begin{array}{l}11.7 \pm 0.5 \\
10.8 \pm 0.5 \\
11.3 \pm 0.4\end{array}$ & $\begin{array}{l}23.3 \pm 1.0 \\
22.4 \pm 1.1 \\
22.9 \pm 0.7\end{array}$ & $\begin{array}{l}28.0 \pm 0.9 \\
27.8 \pm 1.1 \\
27.9 \pm 0.7\end{array}$ & $\begin{array}{l}43.4 \pm 2.8 \\
47.9 \pm 1.3 \\
45.5 \pm 1.7\end{array}$ & $\begin{array}{l}77.2 \pm 2.4 \\
73.4 \pm 3.4 \\
75.4 \pm 2.0\end{array}$ & $\begin{array}{l}433.9 \pm 32.0+ \\
386.1 \pm 26.3 \\
407.8 \pm 20.8\end{array}$ & $\begin{array}{l}63.2 \pm 15.1 \\
24.7 \pm 15.8 \\
42.2 \pm 12.4\end{array}$ \\
\hline
\end{tabular}

*BACs for both groups determined at times corresponding to last alcohol-containing feeding for Group CA on Day 6 and after the last alcohol-free feeding for Group CA on Day 7. †BAC data not available for one male; means based on remaining six males. $¥ B A C$ data not available for two males; means based on remaining five males.

\section{Blood Alcohol Concentrations}

Condensed alcohol exposure resulted in the expected cyclic changes in blood alcohol as measured by the two samples. As indicated in Table 1, the mean BAC after the last feeding fraction that contained alcohol for Group CA (combined sexes) was $407.8 \mathrm{mg} / \mathrm{dl}$ on Day 6 and dropped to $42.2 \mathrm{mg} / \mathrm{dl}$ by the end of the subsequent alcohol-free period. The uniform alcohol exposure resulted in relatively constant and moderate $\mathrm{BACs}$, which averaged $111.8 \mathrm{mg} / \mathrm{dl}$ (combined sexes) for the first sample and $102.2 \mathrm{mg} / \mathrm{dl}$ for the second sample. The repeated measures ANOVA confirmed the statistical significance of the interaction of dose regimen and time of blood sample on BACs $[F(1,19)=548.08, p<.001]$. The differences between the sexes did not reach statistical significance.

\section{Morris Maze Performance}

The use of latencies, path lengths, and initial heading angles as dependent measures, as well as the incorporation of a performance criterion and probe trials, allowed examination of performance from several perspectives. In every case, the rearing condition significantly affected performance: Group CA was severely impaired relative to the Group SC and Group GC controls and to Group UA, with Group UA usually showing mild trends toward poorer performance than the controls. Because every statistical analysis indicated that there were no significant main or interactive effects of sex, the data were combined across sexes within each treatment group for clarity of the graphic presentations.

As shown in Figure 1, Group CA performed significantly worse over days than the other groups, as measured by the mean daily latencies to reach the platform during the Postnatal Day 19-Day 30 training period. The repeated measures ANOVA confirmed a significant effect of rearing condition $[F(3,47)=18.95, p<.001]$, as well as the significant effect of day $[F(11,517)=76.08$, $p<.001]$. Neither the interaction of day $\times$ rearing condition nor, as mentioned above, any terms involving the

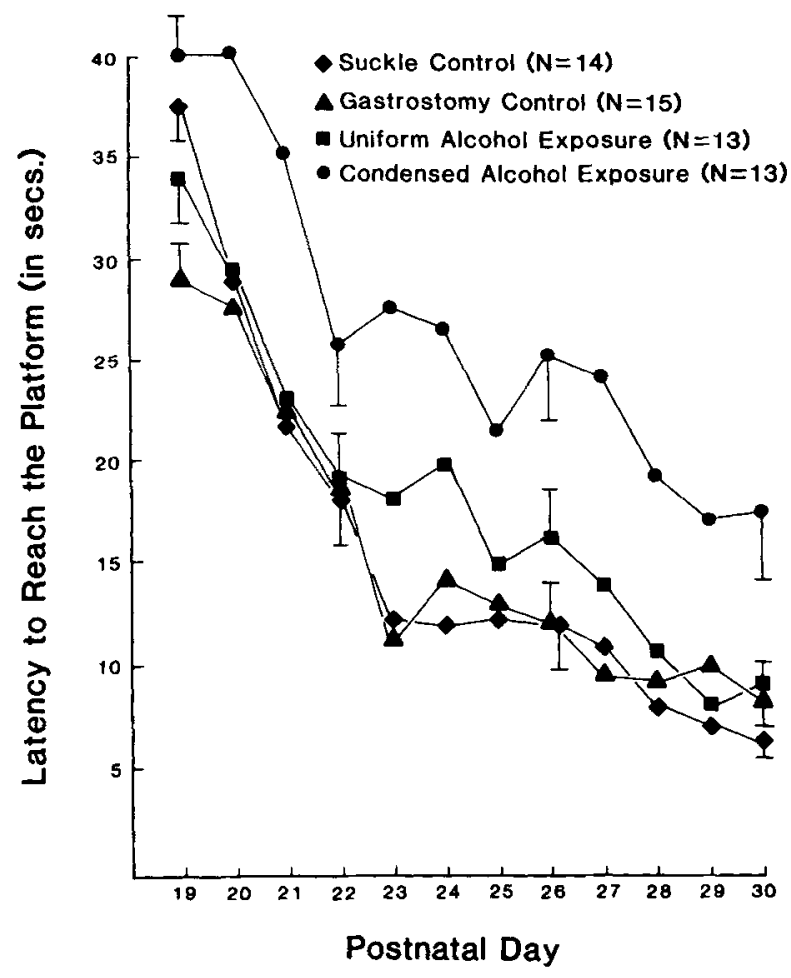

Figure 1. Time to reach the platform in the Morris maze by the four groups of rats on Postnatal Days 19-30. The Latency of the group is the mean for each day, calculated from the average latencies for each individual for the four trials of that day. Error bars represent standard error of the mean (SEM). 
sex factor approached significance. The main effect of rearing condition was due to the poor performance of Group CA: Post hoc comparisons of the marginal means (collapsed over days) indicated that Group CA significantly differed from each of the other groups $(p s<.01)$ and that Groups UA, GC, and SC did not differ significantly from each other.

Analysis of the mean daily path length data from the Day 19-Day 30 training period (shown in Figure 2) yielded the same pattern of effects that the latency analysis had. Only the main effect of rearing condition $[F(3,47)=13.79, p<.001]$ and the main effect of day $[F(11,517)=46.82, p<.001]$ were significant. Group CA had significantly longer path lengths across days than did any of the other three groups $(p<.01$ in each case). The path lengths were more variable than the latencies, and Group UA tended to have longer paths than the two control groups. Nevertheless, the post hoc comparison of marginal means between Group UA and the controls did not reach statistical significance.

The initial heading angles also indicated that Group CA was impaired relative to controls, but in this case Group UA also was impaired (see Table 2). The heading angles generally declined over days for all groups, yielding a significant main effect of day $[F(11,517)=$

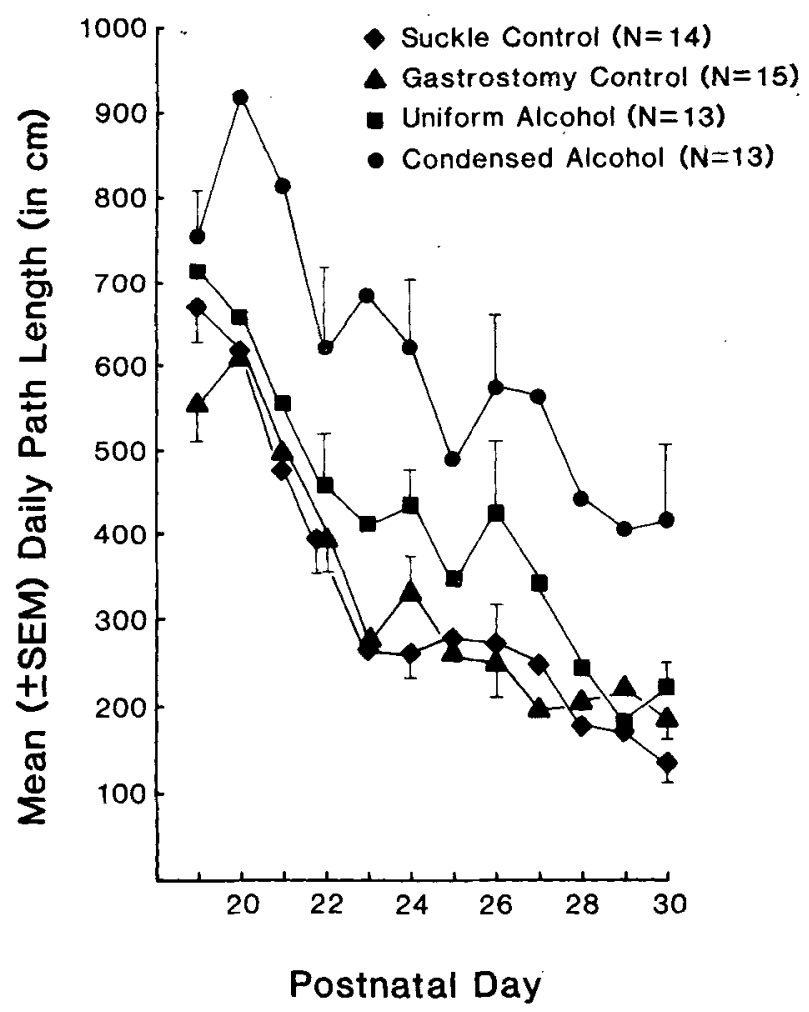

Figure 2. Mean daily path length in the Morris maze of the four groups of rats on Postnatal Days 19-30. Path length of the group is the mean for each day calculated from the average lengths of each individual for the four trials of that day.
Table 2

Mean $( \pm S E M)$ Daily Initial Heading Angles During Acquisition Training

\begin{tabular}{ccccc}
\hline & \multicolumn{4}{c}{ Initial Heading Angle (deg) } \\
\cline { 2 - 5 } Day & Group SC & Group GC & Group UA & Group CA \\
\hline 19 & $58.0 \pm 4.1$ & $59.9 \pm 4.8$ & $58.8 \pm 6.0$ & $64.6 \pm 3.7$ \\
20 & $60.5 \pm 3.2$ & $56.3 \pm 3.9$ & $61.4 \pm 5.2$ & $65.8 \pm 3.8$ \\
21 & $48.6 \pm 3.5$ & $48.2 \pm 3.5$ & $59.8 \pm 3.2$ & $51.8 \pm 3.5$ \\
22 & $47.4 \pm 4.3$ & $49.4 \pm 3.6$ & $54.2 \pm 5.2$ & $54.5 \pm 5.3$ \\
23 & $50.2 \pm 4.4$ & $45.6 \pm 4.8$ & $42.7 \pm 5.9$ & $57.5 \pm 4.2$ \\
24 & $43.8 \pm 5.9$ & $44.5 \pm 3.6$ & $50.5 \pm 5.8$ & $57.7 \pm 4.3$ \\
25 & $41.9 \pm 6.0$ & $45.6 \pm 5.7$ & $49.7 \pm 4.7$ & $56.2 \pm 4.2$ \\
26 & $33.5 \pm 6.1$ & $32.7 \pm 4.8$ & $49.1 \pm 7.2$ & $56.4 \pm 6.0$ \\
27 & $37.4 \pm 3.1$ & $29.7 \pm 3.4$ & $46.5 \pm 6.7$ & $49.5 \pm 5.2$ \\
28 & $29.6 \pm 3.6$ & $40.7 \pm 5.2$ & $50.5 \pm 6.0$ & $40.5 \pm 4.2$ \\
29 & $24.9 \pm 3.2$ & $36.1 \pm 4.7$ & $43.6 \pm 5.9$ & $46.8 \pm 4.1$ \\
30 & $26.7 \pm 3.3$ & $29.7 \pm 3.5$ & $42.0 \pm 5.7$ & $46.1 \pm 5.6$ \\
\hline
\end{tabular}

$14.73, p<.001]$. The main effect of rearing condition also was significant, as in the previous measures $[F(3,47)$ $=5.82, p<.01]$. The post hoc comparisons between the group marginal means indicated that Group CA had wider heading angles than did the controls $(p<.05$ for Group GC; $p<.01$ for Group SC) and did not significantly differ from Group UA. Group UA, in turn, significantly differed from both control groups $(p s<.05$ ). Thus, unlike the other measures, the heading angles did indicate a significant effect of both the uniform alcohol regimen and the condensed regimen on this aspect of spatial performance.

The other performance measures during training confirmed the conclusion derived from the Day 19-Day 30 measures, that Group CA was significantly impaired relative to the other three groups. As shown in Figure 3 (top panel), there was a significant effect of rearing condition on the age at which criterion was reached $[F(3,47)=$ $12.82, p<.001]$, due to the significant delay in Group CA relative to each of the other three $(p s<.01)$. The middle panel of Figure 3 indicates that rearing condition significantly affected the number of criterion days during the Day 19-Day 30 training period $[F(3,47)=$ $14.63, p<.001]$, due to the small number of criterion days of Group CA during this period ( $p s<.01$ relative to the other groups). The mean number of failures to find the platform (Figure 3, lower panel) also showed a significant effect of rearing condition $[F(3,47)=15.78$, $p<.001$, again due to the poorer performance of Group CA $(p s<.01)$. As with most of the other measures of performance, Group UA had a nonsignificant trend toward poorer performance than the control groups.

The effects of the condensed alcohol treatment on place learning are clearly illustrated by representative individual examples. As shown in Figure 4, in which the paths for the acquisition trials on Postnatal Day 27 are depicted for the individuals closest to their respective groups' means, the rat previously exposed to the condensed alcohol regimen was clearly deficient, relative to the gastrostomy control, in directly locating the platform. Interestingly, the 

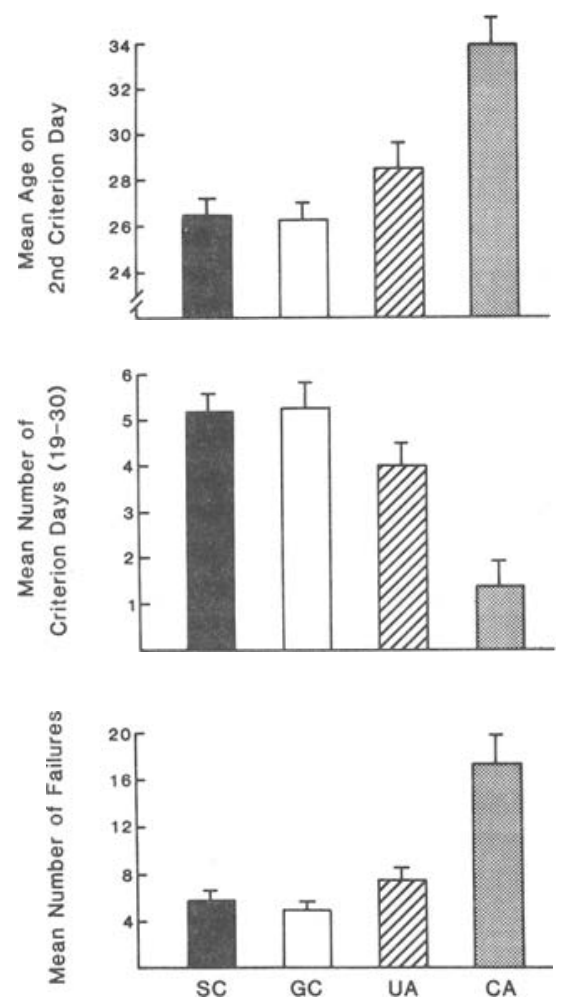

Figure 3. Mean age on 2nd criterion day (top panel), mean number of criterion days during Postnatal Days 19-30 (middle panel), and mean number of failures to find the platform throughout the entire testing period (bottom panel) of the four groups of rats. Groups SC and GC are represented by filled and empty bars, respectively. Groups $U A$ and $C A$ are represented by striped and stippled bars, respectively. Error bars represent $S E M$.

pattern of consecutive loops outward from the wall of the tank frequently was seen in Group CA rats before they acquired criterion level performance.

The probe trials confirmed that the retarded acquisition of the spatial navigation learning of Group CA reflected a retarded development of the use of place strategies. As shown in Figures 5 and 6 on the Postnatal Day 20 probe trials (after 6 acquisition trials), none of the groups showed search strategies that were selective for the appropriate place, as measured by the number of annulus crossings in each quadrant. On the Day 26 probes (after 30 acquisition trials), the Group SC and Group GC controls both had strong biases for searching in the area of the platform (see middle panels of Figures 5 and 6). Group CA failed to show a selective search of the annulus of the appropriate quadrant. Group UA did show the appropriate spatial bias, but the number of annulus crossings in the appropriate crossings was less than for the controls. On the final probe trial (on the last training day), all groups demonstrated place strategies in selectively searching the appropriate area.

The ANOVAs on annulus crossings of the probe trials at each day confirmed the group differences seen in Figure 5. On Postnatal Day 20, there were no significant main or interactive effects in annulus crossings related to quadrant location, which indicated the lack of a place bias by any of the groups. However, there was a significant main effect of rearing condition $[F(3,47)=6.07$, $p<.01$, due to the lower number of crossings of any of the annuli by Group CA than by the other groups $(p<.01)$. This was due to the stronger thigmotaxic behavior of the Group CA rats on Day 20; these rats frequently swam around the perimeter of the tank on the first probe trial (see Figure 6, for example). The ANOVA on the annulus crossings of the Postnatal Day 26 probe trials confirmed the interaction of rearing condition with quadrant location $[F(9,141)=6.69, p<.001]$. For the Group SC and Group GC controls and Group UA, the number of crossings of the annulus in the training quadrant was significantly greater than the number of crossings in the other three quadrants $(p<.01)$. For Group CA, there were no significant differences in annulus crossings due to quadrant location, and the number of crossings of the training annulus was significantly lower than for the controls $(p<.01)$. Although the number of crossings of the annulus in the training quadrant by Group UA was lower than that by the controls, the difference did not reach statistical significance in the post hoc comparisons. The ANOVA on annulus crossings on the last probe trial yielded only a significant effect of quadrant location $[F(3,132)=135.29, p<.001]$, which indicated that all groups showed biases in crossing the annulus in the appropriate (training) quadrant after criterion-level performance had been reached.

\section{DISCUSSION}

In the Morris maze task, the Group SC and Group GC controls acquired efficient levels of performance by Postnatal Day 24 and clearly demonstrated the use of spatial strategies on the probe trials on Day 26. Group CA, which had high, cyclic BACs during the brain growth spurt, was severely impaired on every measure of performance in the development of spatial learning. Group UA, which had relatively constant, moderate BACs during the brain growth spurt, was generally only mildly affected in the development of spatial performance abilities. However, Group UA showed trends toward deficiencies on every measure of spatial learning and was significantly affected in terms of changes in the initial heading angles, which indicated that this regimen of alcohol exposure may have been near the threshold for inducing developmental deficits in this task.

The severe developmental impairment of Group CA was not due to poorer swimming capabilities, because the path lengths were longer in direct proportion to the increased latencies and no obvious swimming difficulties were noted by the experimenters in any of the rats. Rather, their impairment was in the development of the ability to locate the platform effectively via utilization of extramaze spatial cues. The paths during the Day 19-Day 30 acquisition trials were less directed toward the appropri- 


\section{POSTNATAL DAY 27 ACQUISITION (9th TRAINING DAY)}

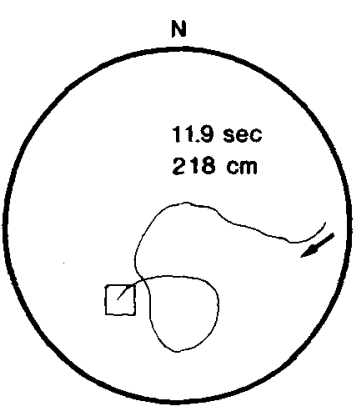

Trial 1

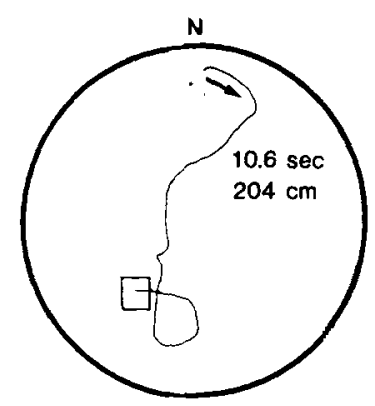

Trial 2

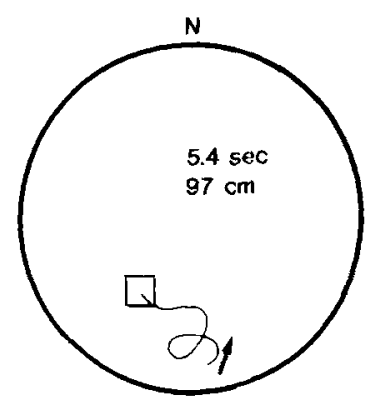

Trial 3

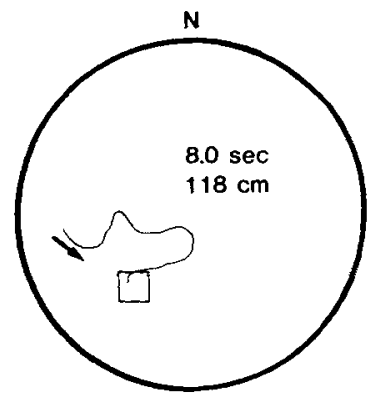

Trial 4

\section{Gastrostomy Control (* 1492.5) ?}

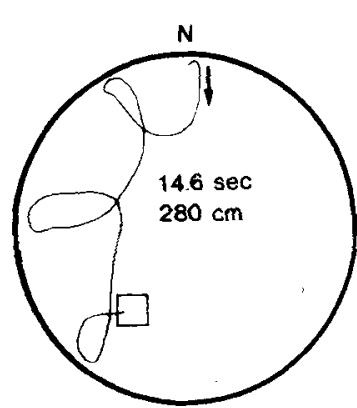

Trial 1

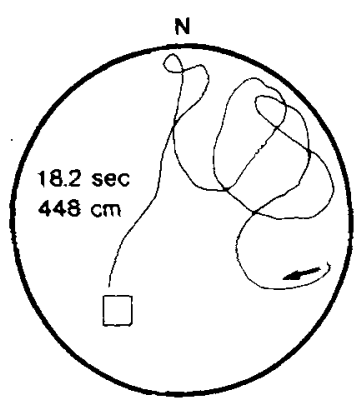

Trial 2

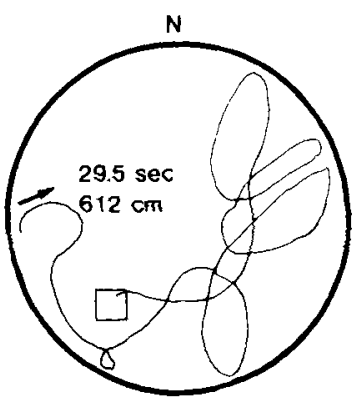

Trial 3

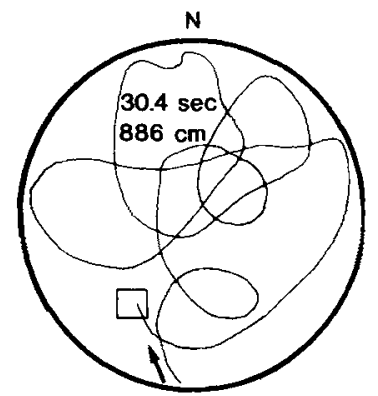

Trial 4

Condensed Alcohol Exposure (* 1503.2) ó

Figure 4. Examples of paths to the platform on the four trials on Postnatal Day 27 of a Group GC rat (upper) and a Group CA rat (lower). The rats chosen for examples were those whose mean daily latencies were closest to their respective groups' means. The latency and distance for each trial are also given.

ate place in the tank, and spatial strategies were not evident during the Day 26 probe trials. Thus, exposure to cyclic BACs with high peaks during Postnatal Days 4-10 severely delayed the development of spatial navigation abilities in this task.

The behavioral data of the present study are the first to demonstrate that the pattern of alcohol exposure is a crucial variable in fetal alcohol effects in the development of learning. The condensed alcohol exposure caused severe deficits in Morris maze learning, whereas the uniform alcohol exposure caused only mild deficits. This same correlation between alcohol-induced deficits and the pattem of exposure has also been found with measures of microencephaly (measured by brain-weight/bodyweight ratios), motor activity, and motor behavior involving fine coordination (Kelly, Hulsether, \& West, 1986; Kelly, Pierce, \& West, in press; West, Kelly, \& Pierce, 1987). Thus, it is becoming increasingly obvious that the extent to which early postnatal alcohol causes damage to the CNS is highly dependent upon the pattern in which the alcohol is administered.

The developmental behavioral impairment of the group exposed to high BACs during Postnatal Days 4-10 implies that the development of the neuronal substrates mediating spatial navigation are significantly affected. However, the extent to which the retarded learning of Group CA was selective for spatial information processing vis-à-vis other, nonspatial forms of learning remains to be examined. In the rat, spatial learning processes have been strongly linked to the hippocampus and related structurcis (O'Keefe \& Nadel, 1978; Olton, 1983; Olton, Becker, \& Handelmann, 1979), along with the medial prefrontal area (Kolb et al., 1983; Sutherland et al., 1982). Our neuromorphological studies indicate that the hippocampus is severely affected by early postnatal alcohol treatment in doses that produce high BACs similar 


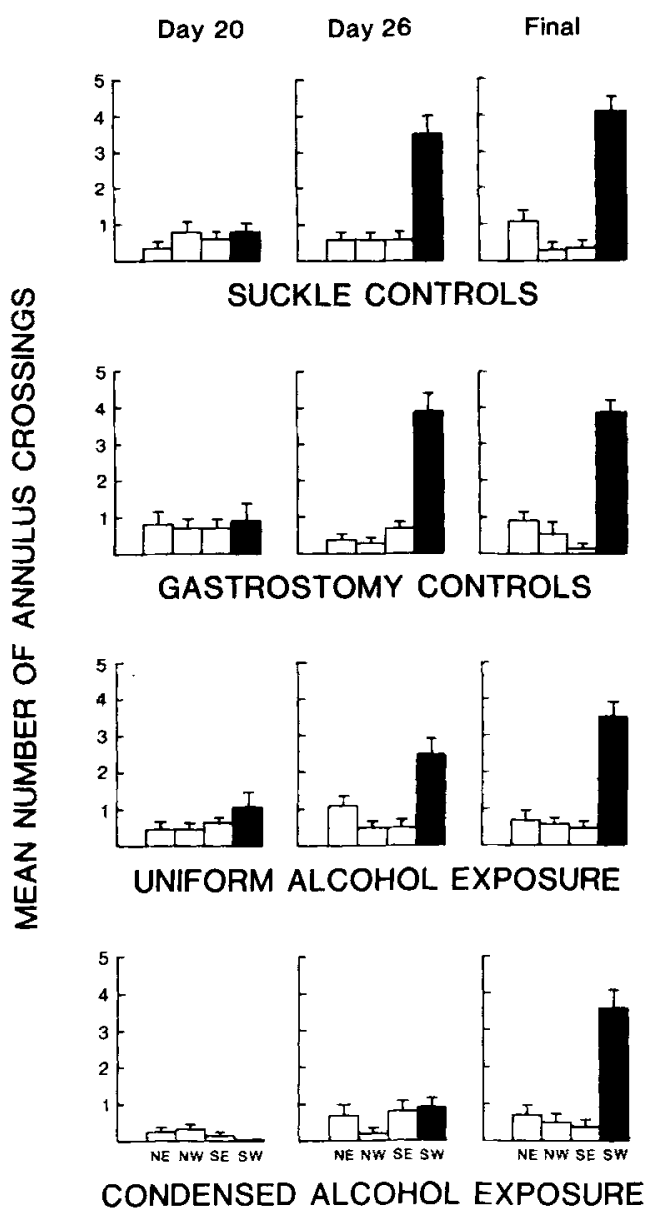

Figure 5. Mean number of crossings of the annulus of the hidden platform in the target quadrant (dark bar) and the annuli of the similar areas of the remaining three quadrants of the tank during the probe trials. The control groups and Group UA demonstrated selective searching on Day 26, whereas Group CA failed to show evidence of selective searching on Day 26 on this measure.

to those in the present study (Pierce \& West, 1986b, in press; West, Hamre, \& Cassell, 1986). Thus, the behavioral outcome is consistent with our previous findings that the structural development of the hippocampus is altered by early alcohol exposure.

Several issues still must be resolved before the proposed correlation between alterations in the hippocampus and retarded development of spatial learning can be confirmed fully. Neurophysiological and neurochemical measures of hippocampal development may bear directly on the nature of the effects of fetal alcohol exposure on the development of the hippocampus. Since mental retardation is the most significant effect of the fetal alcohol syndrome in humans (Streissguth, Landesman-Dwyer, Martin, \& Smith, 1980), it is also important to determine the extent and type of learning deficits and their relationship to CNS damage in animal model systems.

This initial study was designed to examine only the development of place learning, which has been associated with hippocampal function in rats. Given the time and labor investment in the artificial rearing procedure, we did not attempt to dissociate the ontogeny of place learning from the ontogeny of learning based on discrimination of proximal cues, which would require separate experimental groups for an unconfounded design. However, since proximal cue learning in the Morris maze has an earlier developmental onset than does place learning using distal cues (Rudy, Stadler-Morris, \& Albert, in press; Schenk, 1985; Willner, personal communication, September 1986), and can be readily accomplished following hippocampal lesions in adult rats (Morris et al., 1982), the comparison of the developmental onset of place learning and proximal cue learning is an important follow-up to the present study. Since the hippocampal formation is not the only brain region affected by perinatal alcohol exposure (Hammer, 1986; Hammer \& Scheibel, 1981; Miller, 1986; Phillips, 1985, 1986; Pierce \& West, in press; Sherwin, Jacobson, Troxell, Rogers, \& Pelham, 1980; West, Kelly, \& Pierce, 1986), it is important to determine the selectivity of the developmental learning impairment following fetal alcohol exposure. Further examination of the learning abilities of rats treated with alcohol during the brain growth spurt would indicate whether there are effects of early alcohol exposure on both of these types of learning that have different underlying neural substrates, or whether the behavioral retardation is restricted to place learning (e.g., Castro \& Rudy, in press).

One of the difficulties with the developmental training procedure as used in this study is that the learning takes place against a background of a rapidly changing nervous system, and indeed likely depends on the maturation of the hippocampal formation and its extrinsic and intrinsic connections (Dyck et al., 1985). Thus, the detrimental effect of early alcohol exposure cannot be conceived of simply as either a learning deficit or a maturational delay, but instead should be conceived of as an effect on the development of the nervous system that results in this developmental learning disability. Whether, in experimentally naive adult rats, the early alcohol exposure also produces learning deficits, along with any permanent structural and functional damage to the hippocampus, remains to be seen. Nevertheless, the present demonstration of severe impairments in the acquisition of spatial navigation suggests that important milestones in the functional development of the hippocampus may be severely delayed following early alcohol exposure.

There are several factors that may influence teratogenic effects of alcohol on the CNS and the behavioral outcome of fetal alcohol exposure. First, the timing of the alcohol exposure, with respect to the state of the brain development, is undoubtedly important in the type and extent of damage incurred. For example, the morphological evidence presently available suggests that the third trimester equivalent exposure is actually more damaging to the larger, prenatally formed hippocampal pyramidal cells 


\section{PROBE TRIALS}

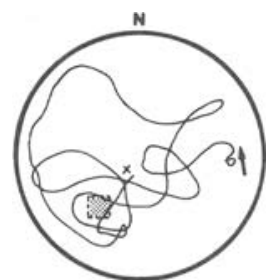

Day 20

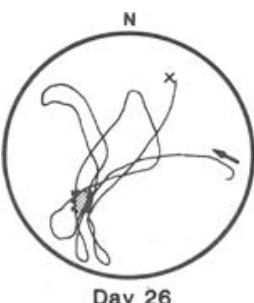

Day 26

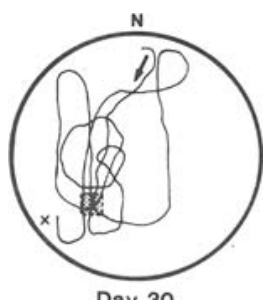

Day 30

Suckle Control $(+1492.1) \sigma$

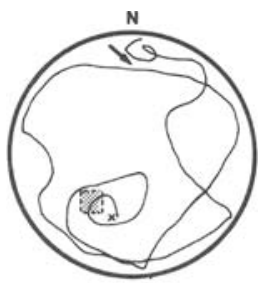

Day 20

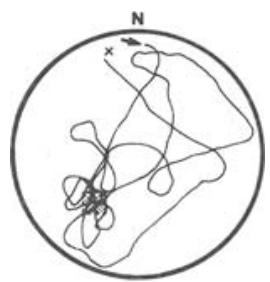

Day 26

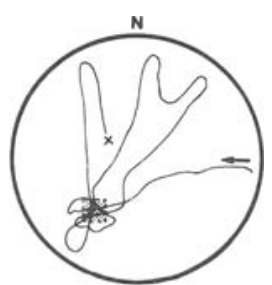

Day 30

Gastrostomy Control (*1505.6) $\sigma$

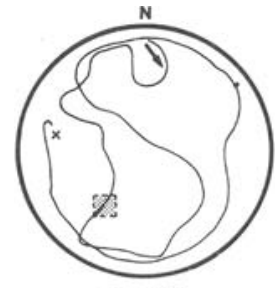

Day 20

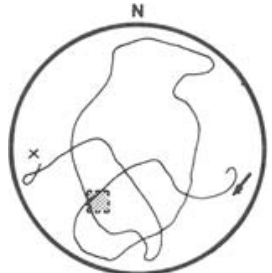

Day 26

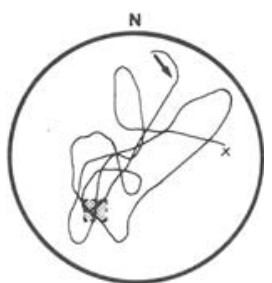

Day 30

Uniform Alcohol Exposure $(* 1312.6) \delta$

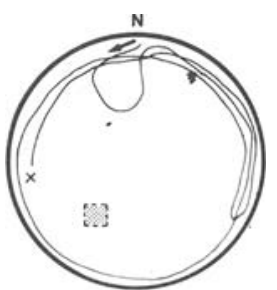

Day 20

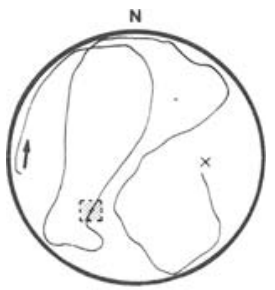

Day 26

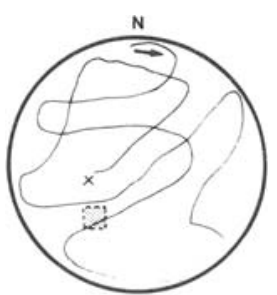

Day 30

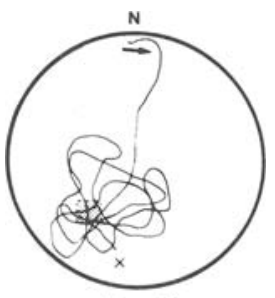

Day 40

Condensed Alcohol Exposure $(* 1494.5) \delta$

Figure 6. Examples of the probe trials (when the platform was removed from the tank) on Postnatal Days 20, 26, and 30 (and Day 40 for the Group CA rat). The rats chosen for these examples were those whose number of crossings of the platform area were most similar to their respective groups' means. The training location of the platform is indicated by the shaded area. 
than to the smaller, postnatally generated granule cells (West, Hamre, \& Cassell, 1986). However, prenatal exposure also has teratogenic effects on the hippocampus (Abel, Jacobson, \& Sherwin, 1983; Barnes \& Walker, 1981; Davies \& Smith, 1981; Dewey \& West, 1985; West, Hodges, \& Black, 1981; West \& Hodges-Savola, 1983), and a recent behavioral report indicates that gestational exposure to alcohol may impair the acquisition of Morris maze learning in rats tested between Postnatal Days 22 and 26 (Blanchard, Riley, \& Hannigan, 1986). Given these findings, it would be interesting to determine whether the effects of both pre- and postnatal alcohol exposure on spatial learning are due to the alcohol's toxic effects on pyramidal cell morphology (e.g., Pierce \& West, in press).

Several factors may play a role in the mechanism(s) of damage to the hippocampal formation following early alcohol exposure. Alcohol may have direct teratogenic effects on various cell populations in the brain. Alternatively (or in addition), the toxicity of alcohol on the CNS may be indirectly mediated through effects on other physiological systems. For example, alcohol may elevate circulating glucocorticoids, and exposure to high glucocorticoid levels during the perinatal period has been shown to alter hippocampal physiology (Vicedomini, Nonneman, DeKosky, \& Scheff, 1985) and performance on spatial learning tasks (DeKosky, Nonneman, \& Scheff, 1982; Vicedomini, Nonneman, DeKosky, \& Scheff, 1986). Perhaps the condensed alcohol administration of the present study resulted in hippocampal dysfunction as a consequence of elevations of glucocorticoids.

In summary, the impaired development of spatial navigation following exposure to high BACs during the brain growth spurt results in a severe delay in the development of spatial learning abilities. Developmental learning disabilities and mental retardation are the most devastating characteristics of the fetal alcohol syndrome in humans (Streissguth et al., 1980). Since our results indicate that behavioral development in a learning task related to hippocampal function is impaired, and since the hippocampus has been implicated in several processes of learning and memory (O'Keefe \& Nadel, 1978; Olton, 1983), this animal model system may provide a tool to understand better the mechanisms and risk factors that contribute to the fetal alcohol effects on brain and behavior. The present study indicates that knowing the total daily exposure to alcohol may not be sufficient to identify the potential risk of fetal alcohol effects, and that the pattern of daily alcohol consumption to the extent that it affects BACs can be an important determinant of the consequences to the fetus.

\section{REFERENCES}

ABEL, E. L., JACOBSON, S., SHERWIN, B. T. (1983). In utero alcohol exposure: Functional and structural brain damage. Neurobehavioral Toxicology \& Teratology, 5, 363-366.

Barnes, D. E., WALKer, D. W. (1981). Prenatal ethanol exposure permanently reduces the number of pyramidal neurons in rat hippocampus. Developmental Brain Research, 1, 333-340.
BAYER, S. A. (1980). The development of the hippocampal region in the rat: $\mathrm{I}$. Neurogenesis examined with ${ }^{3} \mathrm{H}$-thymidine autoradiography. Journal of Comparative Neurology, 190, 87-114.

Blanchard, B. A., Riley, E. P., \& Hannigan, J. H. (1986, November). Deficits on a spatial navigation task following prenatal alcohol exposure. Paper presented at the meeting of The International Society for Developmental Psychobiology, Annapolis, MD.

BoND, N. W. (1986). Fetal alcohol exposure and hyperactivity in rats: The role of the neurotransmitter systems involved in arousal and inhibition. In J. R. West (Ed.), Alcohol and brain development (pp. 4570). New York: Oxford University Press.

BoND, N. W., \&IGIusto, E. L. (1978). Avoidance conditioning and Hebb-Williams maze performance in rats treated prenatally with alcohol. Psychopharmacology, 58, 69-71.

CASTRO, C. A., \& RUDY, J. W. (in press). Early-life malnutrition selectively retards the development of distal- but not proximal-cue navigation. Developmental Psychobiology.

DAVIES, D. L., \& SMTTH, D. E. (1981). A Golgi study of mouse hippocampal CA1 pyramidal neurons following perinatal ethanol exposure. Neuroscience Letters, 26, 49-54.

DeKosky, S. T., Nonneman, A. J., \& SCHefF, S. W. (1982). Morphologic and behavioral effects of perinatal glucocorticoid administration. Physiology \& Behavior, 29, 895-900.

DEWEY, S. L., \& WEST, J. R. (1985). Direct evidence for enhanced axon sprouting in adult rats exposed to ethanol in utero. Brain Research Bulletin, 14, 339-348.

DoBbing, J. (1981). The later development of the brain and its vulnerability. In J. A. Davis \& J. Dobbing (Eds.), Scientific foundations of paediatrics (pp. 744-759). London: Heinemann.

DobBING, J., \& SANDS, J. (1973). Quantitative growth and development of the human brain. Archives of Disease in Childhood, 48, 757-767.

DobBing, J., SANDs, J. (1979). Comparative aspects of the brain growth spurt. Early Human Development, 3, 79-83.

Dyck, R. H., Sutherland, R. J., \& Buday, M. R. (1985). The ontogeny of mapping and non-mapping spatial strategies following neonatal hippocampal damage in rats. Society for Neuroscience Abstracts, 11, 832 .

Geller, L. M., \& GelleR, E. H. (1966). A simple technique for the permanent marking of newborn albino rats. Physiological Reports, 18, 221-222.

Gillam, D. M., Stillanan, A., Dudek, B. C., \& Riley, E. P. (1986). Prenatal alcohol exposure produces learning deficits in mice selected for differential alcohol sensitivity. Alcoholism: Clinical Experimental Research, 10, 112.

Goodlett, C. R., Valentino, M. L., Morgane, P. J., \& Resnick, $O$. (1986). Spatial cue utilization in chronically malnourished rats: Taskspecific learning deficits. Developmental Psychobiology, 19, 1-15.

HAMmer, R. P., JR. (1986). Alcohol effects on developing neuronal structure. In J. R. West (Ed.), Alcohol and brain development (pp. 184-203). New York: Oxford University Press.

HAMmer, R. P., JR., SCHEIBEL, A. B. (1981). Morphologic evidence for a delay of neuronal maturation in fetal alcohol syndrome. Experimental Neurology, 74, 587-596.

JoNEs, K. L., \& SMTtH, D. W. (1973). Recognition of the fetal alcohol syndrome in early infancy. Lancet, 2, 999-1001.

Jones, K. L., Smth, D. W., Ulleland, C. N., \& Streissguth, A. P. (1973). Pattem of malformation in offspring of chronic alcoholic mothers. Lancet, 1, 1267-1271.

Kelly, S. J., Bonthius, D. J., \& WeST, J. R. (in press). Developmental changes in alcohol pharmacokinetics in rats. Alcoholism: Clinical \& Experimental Research.

Kelly, S. J., Hulsether, S. A., \& West, J. R. (1986). Alterations in sensory-motor development: Relationship to postnatal BAC. Manuscript submitted for publication.

Kelly, S. J., Pierce, D. R., \& West, J. R. (in press). Permanency of microencephaly and hyperactivity induced by neonatal alcohol exposure is dependent upon blood alcohol concentration. Experimental Neurology.

KEPPEL, G. (1982). Design and analysis: A researcher's handbook (2nd ed.). Englewood Cliffs, NJ: Prentice-Hall.

Kolb, B., Sutherland, R. J., \& Whishaw, I. Q. (1983). A compari- 
son of the contributions of the frontal and parietal association cortex to spatial localization in rats. Behavioral Neuroscience, 97, 873-889.

Lemoine, P., Harousseau, H., Borteryu, J.-P., \& Menuet, J.-C. (1968). Les enfants de parents alcoholiques: Anomalies observées à propos de 127 cas. Quest Medicale, 21, 476-482.

MiLLER, M. W. (1986). Effects of alcohol on the generation and migration of cerebral cortical neurons. Science, 233, 1308-1311.

MorRIs, R. G. M. (1981). Spatial localization does not require the presence of local cues. Learning \& Motivation, 12, 239-249.

Morris, R. G. M., Garrud, P., Rawlins, J. N. P., \& O'Keefe, J. (1982). Place navigation impaired in rats with hippocampal lesions. Nature, 297, 681-683.

O'KEEFE, J., \& NADEL, L. (1978). The hippocampus as a cognitive map. Oxford: Oxford University Press.

OltoN, D. S. (1983). Memory functions and the hippocampus. In W. Seifert (Ed.), The neurobiology of the hippocampus (pp. 335-373). London: Academic Press.

Olton, D. S., Becker, J. T., \& HandelmanN, G. E. (1979). Hippocampus, space and memory. Behavioral \& Brain Sciences, 2, 313-365.

Phillups, S. C. (1985). Age-dependent susceptibility of rat cerebellar Purkinje cells to ethanol exposure. Drug \& Alcohol Dependency, 16, 273-277.

Phillips, S. C. (1986). Alcohol and histology of the developing cerebellum. In J. R. West (Ed.), Alcohol and brain development (pp. 204224). New York: Oxford University Press.

PIERCE, D. R., \& WEST, J. R. (1986a). Alcohol-induced microencephaly during the third trimester equivalent: Relationship to dose and blood alcohol concentration. Alcohol, 3, 185-191.

PIERCE, D. R., \& WeST, J. R. (1986b). Severity of alcohol-induced deficits in rats during the third trimester equivalent is determined by the pattern of exposure. Alcohol, 3, 269-272.

Pierce, D. R., \& WESt, J. R. (in press). Differential deficits in regional brain growth induced by postnatal alcohol exposure. Neurobehavioral Toxicology \& Teratology.

RILEy, E. P., Barron, S., \& HANnigan, J. H. (1986). Response inhibition deficits following prenatal alcohol exposure: A comparison to the effects of hippocampal lesions in rats. In J. R. West (Ed.), Alcohol and brain development (pp. 71-102). New York: Oxford University Press.

Ruley, E. P., Lochry, E. A., \& ShaPIRo, N. R. (1979). Lack of response inhibition in rats prenatally exposed to alcohol. Psychopharmacology, 62, 47-52.

Rudy, J. W., Stadler-Morris, S., \& Albert, D. (in press). Ontogeny of spatial navigation behaviors in the rat: Dissociation of "proximal" and "distal" cue-based behaviors. Behavioral Neuroscience.

Samson, H. H., \& Diaz, J. (1982). Effects of neonatal ethanol exposure on brain development in rats. In E. L. Abel (Ed.), Fetal alcohol syndrome: Vol. III. Animal studies (pp. 131-150). Boca Raton, FL: CRC Press.

SCHENK, F. (1985). Development of place navigation in rats from weaning to puberty. Behavioral \& Neural Biology, 43, 69-85.

Schlessinger, A. R., Cowan, W. M., \& GotTlieb, D. I. (1975). An autoradiographic study of the time of origin and the pattern of granule cell migration in the dentate gyrus of the rat. Joumal of Comparative Neurology, 159, 149-176.
Schlessinger, A. R., Cowan, W. M., \& Swanson, L. W. (1978). The time of the origin of the neurons in Ammon's horn and associated retrohippocampal fields. Anatomy \& Embryology, 154, 153-173.

Sherwin, B. T., Jacobson, S., Troxell, S. L., Rogers, A. E., \& Pelham, R. W. (1980). A rat model (using a semipurified diet) of the fetal alcohol syndrome. In M. Galanter (Ed.), Currents in alcoholism (Vol. 7, pp. 15-30). New York: Grune \& Stratton.

Streissguth, A. P. (1986). The behavioral teratology of alcohol: Performance, behavioral and intellectual deficits in prenatally exposed children. In J. R. West (Ed.), Alcohol and brain development (pp. 344). New York: Oxford University Press.

Streissguth, A. P., Landesman-Dwyer, S., Martin, J. C., \& Smith, D. W. (1980). Teratogenic effects of alcohol in humans and laboratory animals. Science, 209, 353-361.

SUtHerland, R. J., Kolb, B., \& Whishaw, I. Q. (1982). Spatial mapping: Definitive disruption by hippocampal or medial frontal cortex damage in the rat. Neuroscience Letters, 31, 271-276.

Sutherland, R. J., Whishaw, I. Q., \&olb, B. A. (1983). A behavioral analysis of spatial localization following electrolytic, kainateor colchicine-induced damage to the hippocampal formation in the rat. Behavioral Brain Research, 7, 133-153.

Vicedomini, J. P., Nonneman, A. J., DeKosky, S. T., \& SchefF, S. W. (1985). Perinatal glucocorticoids alter dentate gyrus electrophysiology. Brain Research Bulletin, 15, 111-116.

Vicedomini, J. P., Nonneman, A. J., DeKosky, S. T., \& SchefF, S. W. (1986). Perinatal glucocorticoids disrupt learning: A sexually dimorphic response. Physiology \& Behavior, 36, 145-149.

WEST, J. R. (ED.). (1986). Alcohol and brain development. New York: Oxford University Press.

WEST, J, R., HAMRE, K. M. (1985). Effects of alcohol exposure during different periods of development: Changes in hippocampal mossy fibers. Developmental Brain Research, 17, 280-284.

West, J. R., Hamre, K. M., \& Cassell, M. D. (1986). Effects of ethanol exposure during the third trimester equivalent on neuron number in rat hippocampus and dentate gyrus. Alcoholism: Clinical \& Experimental Research, 10, 190-197.

West, J. R., Hamre, K. M., \& Pierce, D. R. (1984). Delay in brain growth induced by alcohol in artificially reared rat pups. Alcohol, 1, 213-222.

West, J. R., Hodges, C. A., Black, A. C., JR. (1981). Prenatal exposure to ethanol alters the organization of hippocampal mossy fibers in rats. Science, 211, 957-959.

West, J. R., \& Hodges-SA vola, C. A. (1983). Permanent hippocampal mossy fiber hyperdevelopment following prenatal ethanol exposure. Neurobehavioral Toxicology \& Teratology, 5, 139-150.

West, J. R., Kelly, S. J., \& PIERCE, D. R. (1987). Severity of alcoholinduced deficits in rats during the third trimester equivalent is determined by the pattern of exposure. Alcohol \& Alcoholism, Suppl. 1, 461-465.

Whishaw, I. Q., \& KolB, B. (1984). Decortication abolishes place but not cue learning in rats. Behavioural Brain Research, 11, 123-134.

(Manuscript submitted September 22, 1986; revision accepted for publication January 5, 1987.) 